\title{
Pelvic congestion syndrome - treatment with pelvic varicose veins embolization
}

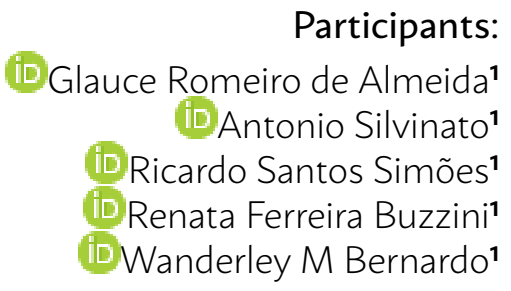

Contact: ricardo.simoes@amb.org.br

Final version: December 7st, 2018

1. Brazilian Medical Association, Rua São Carlos do Pinhal, 324 - Bela Vista, São Paulo - SP, Brasil

http://dx.doi.org/10.1590/1806-9282.65.4.518

The Guidelines Project, an initiative of the Brazilian Medical Association, aims to combine information from the medical field in order to standardize producers to assist the reasoning and decision-making of doctors.

The information provided through this project must be assessed and criticized by the physician responsible for the conduct that will be adopted, depending on the conditions and the clinical status of each patient.

\section{INTRODUCTION}

The etiology of chronic pelvic pain includes irritable bowel syndrome, endometriosis, adenomyosis, pelvic congestion syndrome, atypical menstrual pain, urological disorders, and psychosocial problems ${ }^{1.2}$. One of the underestimated causes of chronic pelvic pain (CPP) in women, especially multiparous at reproductive age, can be pelvic congestion syndrome (PCS), also known as pelvic pain syndrome or pelvic venous incompetence, which is defined as the presence of ovarian and pelvic varicose veins associated with non-cyclical chronic pain in the pelvic region. The pain is present for more than 6 months and is intensified with long periods in orthostatic position, coitus, and menstruation ${ }^{3.4}$. Pelvic varicose veins and CPP are striking characteristics of the PCS, but women diagnosed with pelvic varicose veins can be asymptomatic ${ }^{4}$. The incidence of CPP in women aged between 18 and 50 years was estimated at approximately $20 \%$. It constitutes $10 \%$ to $40 \%$ of all gynecological ambulatory consultations ${ }^{4}$.
In PCS, the pelvic examination can show pelvic sensitivity, congestion of the vaginal walls, and varicose veins $^{5}$. Pelvic varicose veins can be seen in $10 \%$ of women in the general population, and up to $60 \%$ of patients with pelvic varicose veins may develop PCS. Varicose veins can be seen on the vulva, buttocks, and legs ${ }^{6}$.

The PCS is characterized by pelvic varicose veins, causing swelling and venous stasis of the organs of the cavity and, consequently, chronic pain ${ }^{7}$. The venous dysfunction is caused by a multifactor process, within which the increase in intra-abdominal pressure and the action of the female hormones appear to be key factors. These aspects may explain the higher incidence of this syndrome in multiparous women in fertile age and the disappearance of symptoms during the climacteric'.

The left gonadal and right internal iliac veins are the most affected (58\% each) by reflux and in most cases (54\%), there is an insufficiency of more than one major pelvic veins ${ }^{8}$. 
Anatomic abnormalities that obstruct the pelvic venous system can lead to secondary PCS ${ }^{9}$. The extrinsic compression of the left renal vein, blocking the flow to the inferior vena cava (nutcracker phenomenon), is one of the causes to be considered of pelvic varicose veins and insufficiency of the left gonadal vein ${ }^{10}$. By a similar mechanism, the Left Common Iliac Vein Compression Syndrome (May-Thurner) can also be the source of the dysfunction ${ }^{11}$.

Along with the clinical and physical examinations, there are additional resources for the diagnosis of PCS, such as the eco-color Doppler examination (abdominal or transvaginal ultrasound), which provides easier access and allows the dynamic study of the venous flow, with the visualization of venous stasis and reflux ${ }^{12}$. The assessment can also be done through computed tomography angiography (CTA), nuclear magnetic resonance angiography (NMR), laparoscopy, and venography ${ }^{13,14}$. An ovarian vein diameter of $8 \mathrm{~mm}$ in the CTA or NMR is considered a diagnostic of $\mathrm{PCS}^{15}$. Venography is the gold standard for diagnosis, and the following findings must be present: gonadal vein with a diameter $>6 \mathrm{~mm}$; retrograde venous flow; presence of several collateral veins with a tortuous path, and the delay in the drainage of the contrast after the injection'.

The resolution can be surgical (hysterectomy with or without bilateral salpingo-oophorectomy, ligation of ovarian veins), hormonal (medroxyprogesterone), or endovascular (embolization) ${ }^{16-18}$.

Hysterectomy and bilateral oophorectomy with hormone replacement therapy are considered options for an effective cure or at least for the symptomatic improvement of two-thirds of patients with $\mathrm{PCS}^{19}$. This surgical option, however, is not as effective as the ligation of ovarian veins, for which a cure rate of $73 \%$ has been reported and with $78 \%$ of patients presenting symptomatic improvement. However, ligation also sections the nerves of the pelvis and allows the establishment of side effects and recurrence of symptoms ${ }^{29}$.

The use of medroxyprogesterone has been revealing to be the primary therapy, although symptomatic relief is not sustained for a prolonged period ${ }^{20}$.

For the treatment of the PCS, embolization of gonadal veins through a minimally invasive endovascular procedure is performed using the same catheterization of the diagnostic venography. The location of the embolization depends on the presence of collateral circulation. The embolization is performed cen- trally and peripherally ${ }^{21}$. Microcoils of stainless steel or platinum can be used, coated with fibers that induce the formation of blood clots. Several coils can be placed in long varicose veins; it is usually necessary to use 5 to 10 microcoils to embolize all insufficient vessels ${ }^{21.22}$. Currently, controlled-release coils from 6 $\mathrm{mm}$ to $14 \mathrm{~mm}$ are used preferably, since the gonadal vein is approximately $5 \mathrm{~mm}$ wide, and it is important to maintain a margin of oversizing that impedes the displacement of the coil. Other embolization options include the use of foam, glue or sclerosing substances. Once a dilated vein is occluded, venous blood is diverted through other veins of the pelvic region.

\section{METHODOLOGY}

A systematic review was conducted to evaluate the effects of percutaneous endovascular treatment of pelvic congestion syndrome (PCS) through the technique of embolization. The search resulted in 664 articles, of which 29 studies were included. The following search strategy was used: ((pelvic congestion syndrome OR pelvic venous congestion syndrome OR PCS OR Pelvic Pain OR chronic pelvic pain OR Pelvic Veins) AND (pelvic vein embolization OR Embolization, Therapeutic OR Sclerotherapy)) OR ((((embolization OR embolotherapies OR embolotherapy OR embolizations OR embolizations therapeutic))) AND (pelvic OR pelvis OR perirenal) AND (congestion syndrome OR venous insufficiency OR varices $O R$ varicose veins $O R$ pain)) $O R$ ((pelvic congestion syndrome OR pelvic veins OR Pelvic Pain OR chronic pelvic pain) AND (embolisation OR sclerotherapy)).

The measurements used to express the benefit and harm varied according to the outcomes expressed. The continuous variables were analyzed by the mean and standard deviation, and the results were expressed in mean differences between the intervention and the control, with a confidence interval (CI) of $95 \%$.

\section{RESULTS}

A single randomized clinical trial was recovered to answer the clinical question ${ }^{26}$. In this study, of total of 118 randomized patients, 106 (loss of 10\%) women with a diagnosis of PCS were included (90 with left unilateral PVCS, 8 with right unilateral PCS, and 8 with bilateral PCS) confirmed by diagnostic lapa- 
roscopy and venography of the ovarian and internal iliac veins, irresponsive to therapy with medroxyprogesterone acetate (MPA) for 4-6 months. The patients were randomized into 3 groups: embolization of the ovarian vein and/or internal iliac vein with microcoils (Group A, $\mathrm{n}=32$ ), hysterectomy with bilateral oophorectomy and hormone replacement therapy with MPA [Group B, $\mathrm{n}=34$ ] or hysterectomy with unilateral oophorectomy. In group B, five patients with myoma were excluded; in Group C, four patients with adenomyomatosis and three who had had a hysterectomy with unilateral oophorectomy, although they had bilateral involvement. Therefore, a total of 52 patients we analyzed in the "embolization" group, 27 in the hysterectomy with bilateral oophorectomy and hormone replacement therapy group (HBOHR) and 27 in the hysterectomy with unilateral oophorectomy group (HUO). The outcomes evaluated were: pelvic pain using the visual analog scale (VAS), in which the intensity of pain was measured on a visual scale from 0 - 10, with 0 indicating the absence of pain and 10 meaning unbearable pain; pain reduction according to the levels of stress as measured by the revised Social Readjustment Rating Scale (SRRS), which classifies as typical level (100 to 199), moderate/high (200 to 299) and very high level (>300), in a retrospective comparison with the preoperative situation. The complications of the three interventions were also evaluated. The follow-up time was 12 months (Table 1).

The risk of bias for this study ${ }^{25}$ was very high considering the following items: if the issue was focal, appropriate randomization, blinded allocation, double-blind, losses (>20\%), prognostic characteristics, outcomes (time, adequacy, measurement), analysis by intention to treat (ITT), sample size calculation, and JADAD scale ${ }^{23}$ (Table 2).

Embolotherapy compared with hysterectomy and bilateral oophorectomy combined with hormone replacement therapy with medroxyprogesterone reduced pelvic pain, in up to 12 months, evaluated by VAS (ranging from 0 to 10), on average, by 1.4 points (MD) with 95\% confidence interval (CI) of 95\% -1.85 to -0.94; $\mathrm{p}<0.0001$, (Table 3).

In comparison with the unilateral oophorectomy, embolotherapy reduced pelvic pain, in up to 12 months, evaluated by VAS $(0-10)$, on average, by -2.4 (MD); 95\% CI -2.80 to -1.99; $\mathrm{p}<0.0001$ (Table 4).

This $\mathrm{RCT}^{25}$ does not provide data on mean and SD, concerning pain in different scores of stress (Revised
Social Readjustment Rating Scale) for the periods of postoperative follow-up, thus preventing a comparison of different interventions for this outcome.

In the embolotherapy group, there were two patients $(3.84 \%)$ that presented migration of one coil (one for the pulmonary circulation and the other for the renal circulation), but there was no death.

There was 1 complication in the hysterectomy with bilateral oophorectomy group and 1 complication in the hysterectomy with unilateral oophorectomy group, however, there is no reference to the type of complication. There was no death in these groups.

Adverse events with embolotherapy in case series studies

The results of 28 series of cases ${ }^{8,22,26-51}$ showed the following complications from the embolization of pelvic varicose veins in the treatment of PCS: migration of coils to the pulmonary circulation with embolism and symptomatic or asymptomatic patients; migration of coils to the right external iliac arc vein or left renal vein; migration of glue fragment to the pulmonary circulation with embolism; venous perforation (ovarian vein, common iliac vein, internal iliac vein). However, there was no death in these studies.

\section{SUMMARY OF THE RESULTS}

This guideline aimed to identify, assess, and quantify the benefit and the harm from the use of percutaneous embolization (coils, foam, glue or sclerosing substances) of pelvic veins (ovarian and/or internal iliac veins or other collaterals) in women with PCS, as a method of treatment, compared to other treatment options.

The search for evidence retrieved 664 papers, of which 29 were selected to support the conclusions. Stratifying by study design, 1 (one) randomized controlled clinical trial ${ }^{25}$, and 28 (twenty-eight) series of cases were included ${ }^{8,22,26-51}$.

The randomized controlled clinical trial was used to evaluate the effectiveness and harm, and the series of cases only for complications.

The only randomized controlled clinical trial included in this guideline presents a very high risk of bias (Table 2).

In this study, embolotherapy compared with hysterectomy and bilateral oophorectomy combined with hormone replacement therapy with medroxyprogesterone reduced pelvic pain in up to 12 months, on av- 
erage, by 1.4 points $95 \%$ CI -1.85 to -0.94 , p < 0.0001 in the evaluation using VAS, which ranged from 0 - 10 points, therefore, with a very small magnitude of effect. STRENGTH OF EVIDENCE VERY WEAK.

In comparison with the unilateral oophorectomy, embolotherapy reduced pelvic pain, in up to 12 months, evaluated by VAS (0 - 10), on average, by -2.4; $95 \%$ CI -2.80 to -1.99 ; $p<0.0001$, with a small magnitude of the effect. STRENGTH OF EVIDENCE VERY WEAK.
Although no deaths occurred, the complications found in the randomized clinical trial25 and in the 28 series of cases8,22,26-51, that used percutaneous embolization (coils, foam, glue or sclerosing substances) of pelvic veins (ovarian and/or internal iliac veins or other collaterals) in women with PCS were: migration of coils to the pulmonary circulation with embolism and symptomatic or asymptomatic patients; migration of coils to the right external iliac vein or left renal vein; migration of glue fragment

TABLE 1. DESCRIPTIVE TABLE OF THE CHARACTERISTICS OF THE RCT STUDY

\begin{tabular}{|c|c|c|c|c|c|}
\hline STUDY & POPULATION (N) & INTERVENTION (N) & COMPARISON (N) & OUTCOME & $\begin{array}{l}\text { FOLLOW-UP } \\
\text { TIME }\end{array}$ \\
\hline $\begin{array}{l}\text { Chung } \\
\mathrm{MH} \text {, et al., } \\
2003^{25}\end{array}$ & $\begin{array}{l}\text { Included } 106 \text { women with a } \\
\text { diagnosis of PVI, confirmed } \\
\text { by diagnostic laparoscopy and } \\
\text { venography of the ovarian and } \\
\text { internal iliac veins, irresponsive } \\
\text { to MPA for } 4-6 \text { months. } \\
\text { Exclusion: other pathologies } \\
\text { (myoma, endometriosis, adher- } \\
\text { ence). } \\
\text { Excluded: } \\
\text { - Group B: } n=5 \text { (myoma) } \\
\text { - Group C: } n=7 \text { ( } 4 \text { due to adeno- } \\
\text { myomatosis and } 3 \text { who had had } \\
\text { unilateral oophorectomy and } \\
\text { hysterectomy although they had } \\
\text { bilateral involvement) }\end{array}$ & $\begin{array}{l}\text { Group A: Embolization } \\
\text { of the ovarian and/or } \\
\text { internal iliac vein with } \\
\text { microcoils }(n=52)\end{array}$ & $\begin{array}{l}\text { Group B: Hysterec- } \\
\text { tomy with bilateral } \\
\text { oophorectomy and } \\
\text { hormone replacement } \\
\text { therapy ( } 32 \text { random- } \\
\text { ized and included } \\
\mathrm{n}=27 \text { ) } \\
\text { Group C: Hysterec- } \\
\text { tomy with unilateral } \\
\text { oophorectomy ( } 34 \\
\text { randomized and } \\
\text { included } \mathrm{n}=27 \text { ) }\end{array}$ & $\begin{array}{l}\text { - Pain (VAS) } \\
\text { - Reduction of pain } \\
\text { (VAS) per levels of stress } \\
\text { (SRRS): retrospective } \\
\text { Comparison with preop- } \\
\text { erative situation } \\
\text { - Complications }\end{array}$ & $\begin{array}{l}3,6 \text {, and } 12 \\
\text { months }\end{array}$ \\
\hline
\end{tabular}

MPA = medroxyprogesterone acetate; PVI = pelvic venous insufficiency; VAS = visual analogue scale; SRRS = Revised Social Readjustment Rating Scale [classifies the level of stress: typical level (100 to 199), moderate/high level (200 to 299), very high level (>300)]

TABLE 2. DESCRIPTIVE TABLE OF THE BIASES IN THERAPEUTIC STUDIES (CHUNG MH, ET AL., 200325)

\begin{tabular}{|c|c|c|c|c|c|c|c|c|}
\hline STUDY & $\begin{array}{l}\text { FOCAL } \\
\text { ISSUE }\end{array}$ & $\begin{array}{l}\text { RANDOM- } \\
\text { IZATION }\end{array}$ & $\begin{array}{l}\text { BLINDED } \\
\text { ALLOCATION }\end{array}$ & BLINDING & LOSSES & $\begin{array}{l}\text { PROGNOSTIC } \\
\text { DIFFERENCES }\end{array}$ & $\begin{array}{l}\text { OUTCOMES } \\
\text { (risk of bias) }\end{array}$ & ITT \\
\hline $\begin{array}{l}\text { Chung } M H \text {, } \\
\text { et al., } 2003\end{array}$ & Yes & Not described & No & No & $\begin{array}{l}10 \% \text { excluded after } \\
\text { randomization (reasons } \\
\text { reported) }\end{array}$ & Yes & Yes & No \\
\hline
\end{tabular}

ITT = intention-to-treat analysis; ADAD $^{23}=1 ;$ SAMPLE SIZE CALCULATION: There was none

TABLE 3. DESCRIPTIVE TABLE OF THE RESULTS (CHUNG MH, ET AL., 200325)

\begin{tabular}{l|l|l|l|l|l} 
OUTCOME & $\begin{array}{l}\text { (N) - Mean } \pm \\
\text { SD on EMBO- }\end{array}$ & $\begin{array}{l}\text { (N) - Mean } \pm \text { SD in hysterectomy } \\
\text { with bilateral oophorectomy and } \\
\text { hormonal replacement therapy }\end{array}$ & \multicolumn{1}{c}{$\begin{array}{l}\text { Mean differences } \\
\text { (MD) }\end{array}$} & Cl 95\% \\
\hline $\begin{array}{l}\text { Pain (VAS score) } \\
\text { in } 12 \text { months }\end{array}$ & $(\mathrm{N}=52)$ & $(\mathrm{N}=27)$ & -1.4 & $-1.85 \mathrm{a}-0.94$ \\
\hline
\end{tabular}

VAS - visual analog scale of pain (score $\mathrm{O}$ to 10 ); $\mathrm{SD}=$ standard deviation; $\mathrm{Cl}=$ confidence interval

TABLE 4. DESCRIPTIVE TABLE OF THE RESULTS (CHUNG MH, ET AL., 200325)

\begin{tabular}{|c|c|c|c|c|c|}
\hline OUTCOME & $\begin{array}{l}(\mathrm{N})-\text { Mean } \pm \text { SD on } \\
\text { EMBOLOTHERAPY }\end{array}$ & $\begin{array}{l}(\mathrm{N}) \text { - Mean } \pm \mathrm{SD} \text { in hys- } \\
\text { terectomy with unilateral } \\
\text { oophorectomy }\end{array}$ & Mean differences & $\mathrm{Cl} 95 \%$ & P-value \\
\hline $\begin{array}{l}\text { Pain (VAS score) } \\
\text { in } 12 \text { months }\end{array}$ & $\begin{array}{l}(N=52) \\
3.2 \pm 0.9\end{array}$ & $\begin{array}{l}(N=27) \\
5.6 \pm 0.8\end{array}$ & -2.4 & $-2.80 a-1.99$ & $<0.0001$ \\
\hline
\end{tabular}


to the pulmonary circulation with embolism; venous perforation (ovarian vein, common iliac vein, internal iliac vein). STRENGTH OF EVIDENCE VERY WEAK

\section{RECOMMENDATION}

This guideline had access to a single randomized controlled clinical trial, with a high risk of bias, and no other comparative study for the eval-

\section{REFERENCES}

1. Liddle AD, Davies AH. Pelvic congestion syndrome: chronic pelvic pain caused by ovarian and internal iliac varices. Phlebology 2007;22(3):100-4.

2. Cheong Y, William Stones R. Chronic pelvic pain: aetiology and therapy. Best Pract Res Clin Obstet Gynaecol 2006;20(5):695-711.

3. Gunter J. Chronic pelvic pain: an integrated approach to diagnosis and treatment. Obstet Gynecol Surv 2003 Sep:58:615-23. Review. PMID: 12972837.

4. Harris RD, Holtzman SR, Poppe AM. Clinical outcome in female patients with pelvic pain and normal pelvic US findings. Radiology 2000;216:4403. PMID: 10924567.

5. Cura M, Cura A. What is the significance of ovarian vein reflux detected by computed tomography in patients with pelvic pain? Clin Imaging 2009;33:306-10.

6. Karcaaltincaba M, Karcaaltincaba D, Dogra V. Pelvic congestion syndrome. Ultrasound Clin 2008;3:415-25.

7. Liddle $A D$, Davies $A H$. Pelvic congestion syndrome: chronic pelvic pain causes by ovarian and internal iliac varices. Phlebology 2007;22:100-4. PMID: 18268860

8. Asciutto $G$, Asciutto KC, Mumme A, Geier B. Pelvic venous incompetence: reflux patterns and treatment results. Eur J Vasc Endovasc Surg 2009;38:381-6. PMID: 19574069.

9. Ignacio EA, Dua R 4th, Sarin $S$, et al. Pelvic congestion syndrome: diagnosis and treatment. Semin Intervent Radiol 2008;25:361-8. PMID: 21326577

10. Kurklinsky AK, Rooke TW. Nutcracker phenomenon and nutcracker syndrome. Mayo Clin Proc 2010;85:552-9. PMID: 20511485

11. Lou WS, Gu IP, He X, et al. Endovascular treatment for iliac vein compression syndrome: a comparison between the presence and absence of secondary thrombosis. Korean I Radiol 2009;10:135-43. PMID: 19270859.

12. Freedman I, Ganeshan A, Crowe PM. Pelvic congestion syndrome: the role of interventional radiology in the treatment of chronic pelvic pain. Postgrad Med J 2010;86:704-10. PMID: 21106807.

13. Stones RW, Rae T, Rogers V, Fry R, Beard RW. Pelvic congestion in women: evaluation with transvaginal ultrasound and observation of venous pharmacology. Br | Radiol 1990;63:710-1.

14. Perry CP. Current concepts of pelvic congestion and chronic pelvic pain. ISLS 2001;5:105-10.

15. Bhutta H, Walsh S, Tang T, Walsh C, Clarke I. Ovarian vein syndrome: a review. Int J Surg 2009;7:516-20.

16. Edwards RD, Robertson IR, MacLean AB, Hemingway AP. Case report: pelvic pain syndrome--successful treatment of a case by ovarian vein embolization. Clin Radiol 1993;47:429-31.

17. Carter JE. Surgical treatment for chronic pelvic pain. JSLS. 1998;2:129-39.

18. Swanton A, Reginald P. Medical management of chronic pelvic pain: the evidence. Rev Gynaecol Pract 2004;4:65-70.

19. Beard RW, Reginald PW, Wadsworth J. Clinical features of women with chronic lower abdominal pain and pelvic congestion. Br | Obstet Gynaeco 1998;95:153-61.

20. Swanton A, Reginald P. Medical management of chronic pelvic pain: the evidence. Rev Gynaecol Pract 2004;4:65-70.

21. Boomsa JHB, Potocky V, Kievit CEL et al. Phebography and embolization in women with pelvic vein insuffiency. Medicamundi 1998: 42 22-29. uation of the evidence (effectiveness and harm) of percutaneous endovascular treatment in pelvic congestion syndrome using the technique of embolization. Therefore, the results are associated with a high degree of uncertainty which hinders the establishment of a firm conclusion that allows this procedure to be considered a standard treatment option for PCS. (STRENGTH OF EVIDENCE VERY WEAK)

22. Creton D, Hennequin L, Kohler F, Allaert FA. Embolisation of Symptomatic Pelvic Veins in Women Presenting with Non-saphenous Varicose Veins of Pelvic Origin: Three-year Follow-up. Eur J Vasc Endovasc Surg 2007:34, 112-117.

23. Jadad AR, Moore RA, Carroll D, Jenkinson C, Reynolds D|, Gavaghan D|, et al. Assessing the quality of reports of randomized clinical trials: is blinding necessary? Control Clin Trials 1996; 17:1-12

24. Guyatt G, Gutterman D, Baumann MH, Addrizzo-Harris D, Hylek EM, Phillips B et al. Grading strength of recommendations and quality of evidence in clinical guidelines: report from an american college of chest physicians task force. Chest 2006;129(1):174-81. PMID: 16424429

25. Chung $\mathrm{MH}$, Huh $\mathrm{CY}$. Comparison of treatments for pelvic congestion syndrome. Tohoku J Exp Med. 2003;201:131-8. PMID: 14649734

26. Dorobisz TA, Garcarek JS, Kurcz J, Korta K, Dorobisz AT, Podgórski P, et al. Diagnosis and treatment of pelvic congestion syndrome: Single-centre experiences. Adv Clin Exp Med 2017;26:269-276. PMID: 28791845

27. Marcelin C, Izaaryene J, Castelli M, Barral PA, Jacquier A, Vidal V, et al. Embolization of ovarian vein for pelvic congestion syndrome with ethylene vinyl alcohol copolymer (Onyx $\left({ }^{\circledR}\right)$ ). Diagn Interv Imaging 2017;98:843-848. PMID: 28647478

28. Abdelsalam $\mathrm{H}$. Clinical outcome of ovarian vein embolization in pelvic congestion syndrome. Alexandria Journal of Medicine 2017;53:15-20

29. Pyra K, Woźniak S, Drelich-Zbroja A, Wolski A, Jargiełło T. Evaluation of Effectiveness of Embolization in Pelvic Congestion Syndrome with the New Vascular Occlusion Device (ArtVentive EOSTM): Preliminary Results. Cardiovasc Intervent Radiol 2016:39:1122-7. PMID: 27250353

30. Siqueira FM, Monsignore LM, Rosa-E-Silva JC, Poli-Neto OB, Castro-Afonso LH, Nakiri GS, et al. Evaluation of embolization for periuterine varices involving chronic pelvic pain secondary to pelvic congestion syndrome. Clinics (Sao Paulo). 2016 1;71:703-708. PMID: 28076514

31. Pyra K, Woźniak S, Roman T, Czuczwar P, Trojanowska A, Jargiełło T, et al. Evaluation of effectiveness of endovascular embolisation for the treatment of pelvic congestion syndrome--preliminary study. Ginekol Pol 2015;86:346-51. PMID: 26117971

32. Edo Prades MA, Ferrer Puchol MD, Esteban Hernández E, Ferrero Asensi M. Pelvic congestion syndrome: outcome after embolization with coils. Radiologia 2014;56:235-40. PMID: 22633116

33. Hocquelet A, Le Bras Y, Balian E, Bouzgarrou M, Meyer M, Rigou G, et al. Evaluation of the efficacy of endovascular treatment of pelvic congestion syndrome. Diagn Interv Imaging. 2014;95:301-6. PMID: 24183954

34. Nasser F, Cavalcante RN, Affonso BB, Messina ML, Carnevale FC, de Gregorio MA. Safety, efficacy, and prognostic factors in endovascular treatment of pelvic congestion syndrome. Int | Gynaecol Obstet 2014;125:65-8. PMID: 24486124

35. Gandini R, Konda D, Abrignani S, Chiocchi M, Da Ros V, Morosetti D, et al.Treatment of symptomatic high-flow female varicoceles with stop-flow foam sclerotherapy. Cardiovasc Intervent Radiol 2014;37:1259-67. PMID: 24190634

36. Laborda A, Medrano |, de Blas I, Urtiaga I, Carnevale FC, de Gregorio MA Endovascular treatment of pelvic congestion syndrome: visual analog scale (VAS) long-term follow-up clinical evaluation in 202 patients. Cardiovasc Intervent Radiol 2013;36:1006-14. PMID: 23456353

37. van der Vleuten C|, van Kempen |A, Schultze-Kool LJ. Embolization to treat pelvic congestion syndrome and vulval varicose veins. Int J Gynaecol Obstet 2012;118:227-30. PMID: 22727416 
38. Asciutto G, Asciutto KC, Mumme A, Geier B. Pelvic venous incompetence: reflux patterns and treatment results. Eur J Vasc Endovasc Surg. 2009;38:381-6. PMID: 19574069

39. Gandini R, Chiocchi M, Konda D, Pampana E, Fabiano S, Simonett G. Transcatheter foam sclerotherapy of symptomatic female varicocele with sodium-tetradecyl-sulfate foam. Cardiovasc Intervent Radiol. 2008;31:778-84. PMID: 18172712

40. Tropeano G, Di Stasi C, Amoroso S, Cina A, Scambia G. Ovarian vein incompetence: a potential cause of chronic pelvic pain in women. Eur $\mathbf{O} \mathrm{Ob}$ stet Gynecol Reprod Biol 2008;139:215-21. PMID: 18313828

41. Creton D, Hennequin L, Kohler F, Allaert FA. Embolisation of symptomatic pelvic veins in women presenting with non-saphenous varicose veins of pelvic origin - three-year follow-up. Eur J Vasc Endovasc Surg 2007;34:1127. PMID: 17336555

42. Kwon $\mathrm{SH}$, Oh JH, Ko KR, Park HC, Huh JY. Transcatheter ovarian vein embolization using coils for the treatment of pelvic congestion syndrome. Cardiovasc Intervent Radiol 2007;30:655-61. PMID: 17468903

43. Kim HS, Malhotra AD, Rowe PC, Lee IM, Venbrux AC. Embolotherapy for pelvic congestion syndrome: long-term results. J Vasc Interv Radiol 2006;17:289-97. PMID: 16517774

44. Bachar GN, Belenky A, Greif F, Atar E, Gat Y, Itkin M, et al. Initial experience with ovarian vein embolization for the treatment of chronic pelvic pain syndrome. Isr Med Assoc | 2003;5:843-6. PMID: 14689749

45. Pieri S, Agresti P, Morucci M, de' Medici L. Percutaneous treatment of pelvic congestion syndrome. Radiol Med 2003;105:76-82. PMID: 12700549
46. Pisco |M, Alpendre |, Santos DD, Branco |, Jorge R, Albino |P, Menezes |D. Sclerotherapy of female varicocele. Acta Med Port 2003;16:9-12. PMID: 12828000

47. Venbrux AC, Chang AH, Kim HS, Montague BJ, Hebert JB, Arepally $A$, et al. Pelvic congestion syndrome (pelvic venous incompetence): impact of ovarian and internal iliac vein embolotherapy on menstrual cycle and chronic pelvic pain. J Vasc Interv Radiol 2002;13:171-8. PMID: 11830623

48. Maleux G, Stockx L, Wilms G, Marchal G. Ovarian vein embolization for the treatment of pelvic congestion syndrome: long-term technical and clinical results. J Vasc Interv Radiol 2000;11:859-64. PMID: 10928522

49. Cordts PR, Eclavea A, Buckley PJ, DeMaioribus CA, Cockerill ML, Yeager TD. Pelvic congestion syndrome: early clinical results after transcatheter ovarian vein embolization. J Vasc Surg 1998;28:862-8. PMID: 9808854

50. Tarazov PG, Prozorovskij KV, Ryzhkov VK. Pelvic pain syndrome caused by ovarian varices. Treatment by transcatheter embolization. Acta Radiol 1997;38:1023-5. PMID: 9394662

51. Capasso P, Simons C, Trotteur G, Dondelinger RF, Henroteaux D, Gaspard $U$. Treatment of symptomatic pelvic varices by ovarian vein embolization. Cardiovasc Intervent Radiol 1997;20:107-11. PMID: 9030500

52. Levels of Evidence and Grades of Recommendations - Oxford Centre for Evidence Based Medicine. Disponível em URL: http://cebm.jr.ox.ac.uk/ docs/old levels.htm 